\title{
Greenhouse Environmental Control Using Optimized, Modeled and Simulated Fuzzy Logic Controller Technique in MATLAB SIMULINK
}

\author{
Didi Faouzi ${ }^{1}$, N. Bibi-Triki ${ }^{2}$, B. Draoui ${ }^{3}$ and A. Abène ${ }^{4}$ \\ 1. Faculty of Science and Technology, Department of Physics, University of Abou-bakr Belkaï, B.P. 119, Tlemcen, Algeria \\ 2. Materials and Renewable Energy Research Unit M.R.E.R.U., University of Abou-bakr Belkaïd, B.P. 119, Tlemcen, Algeria \\ 3. Energy Laboratory in Drylands, University of Bechar, Bechar, Algeria \\ 4. Euro-Mediterranean Institute of Environment and Renewable Energies, University of Valenciennes, France
}

\begin{abstract}
The main objective of this study is the control of the agricultural greenhouse in view of the economic interest generated by such an activity. A simulation model is developed, gathering all the external and internal climatic conditions that influence the microclimate of the greenhouse to predict the temporal evolution of the state variables characterizing this microclimate. The fuzzy control is an alternative to the approaches proposed by the automatic for the control of complex systems. The performance objectives of the looped systems and the corresponding actions are summarized in the form of rules of expertise, which are spelled out in plain language. This technique thus makes it possible to dispense with the use of mathematical models which are sometimes difficult to obtain. Our objective is the multivariable strategy synthesis and the fuzzy application to a multivariate system (MIMO ${ }^{\circ}$ such as the agricultural greenhouse.) First, the principles of fuzzy logic and fuzzy control are recalled. The origins of non-Linearitys of the command are explained. One of the practical problems of this technique is the combinatorial explosion of the rule base when the number of variables involved becomes large. A solution to simplify the complexity of the system is presented together with an optimization algorithm to automatically adjust the parameters of the fuzzy controller. The last part is devoted to the synthesis of an optimal control of the greenhouse in order to compare it to the fuzzy control implemented.
\end{abstract}

Key words: Greenhouse, microclimate, modeling, fuzzy controller, optimization, solar energy, climate model, temperature.

\section{Introduction}

Agricultural greenhouse originally designed as a simple enclosure limited by a transparent wall, as is the case for conventional tunnel greenhouses and largely answered chapel in several countries including those of the Mediterranean basin. They amplify certain characteristics of the surrounding environment, thus involving variations of internal energy and fairly significant heat loss due to the low inertia [1] of the clamp system.

To maintain a microclimate suited to the demands of the protected culture, energy intake and the introduction of new technologies and air conditioning

Corresponding author: Didi Faouzi, Ph.D., research field: physics specialty renewable energies. operation becomes necessary and essential, to do so faces the challenge of supply and demand of agricultural products fresh throughout the year for a strictly increasing population.

We are interested in this product conditioning of agricultural greenhouse while characterizing the dynamic operation of the complex system that is the greenhouse with its various compartments [2], develop models to reproduce the essential properties, mechanisms and interactions in different compartments and to approach the analysis of thermo-fluid behavior of agricultural greenhouse.

New climate techniques have emerged, including the use of regulation devices ranging from classical to the use of artificial intelligence [3], such as neural 
networks and/or fuzzy logic, etc.

Many facilities have been designed to regulate and monitor climate variables in an agricultural greenhouse [4, 5], such as: Temperature, Humidity, $\mathrm{CO}_{2}$ concentration, Irrigation, the ventilation [6], etc. The possibilities offered by greenhouse climate computers have solved the problems relating to the regulation and respect of climate instructions required by protected cultivation.

The climate computer greenhouse will have to be integrated as a tool for dynamic management of production, able to choose the most appropriate climate route, meet objectives and production orders, while minimizing inputs.

The complexity of managing and optimizing [7] this environment cannot be addressed only through a comprehensive approach to operating greenhouses-systems.

Greenhouse management and the urgent and varied consumer demand make the problem multivariable, nonlinear and highly complex $[8,9]$.

\section{Modeling the Greenhouse}

This article deals with the modeling and simulation of our greenhouse model which is based on the method of GUESS [10].

GUESS is a model set in parameter block, meaning that spatial heterogeneity is ignored and it is assumed that the inner content and the flow through the system boundary are evenly distributed. .

The conservation equations are used to model the rate of system status change.

- For a warm greenhouse these state variables would be the indoor temperature, relative humidity, air pressure and $\mathrm{CO}_{2}$ concentration.

- For the plant state variables are the water content, the body temperature, dry weight or biomass, and internally sheet $\mathrm{CO}_{2}$.

A complete equation for the transport of some scalar quantity through a control volume is as following:

$$
C V \frac{\partial \Phi}{\partial x}=A\left(F_{\text {int }}-F_{\text {out }}\right)+V\left(Q_{\text {source }}-Q_{\text {sink }}\right)
$$

$C$ : The heat capacity $\left(\mathrm{J} / \mathrm{m}^{3} \cdot \mathrm{k}\right)$;

$V$ : System Volume $\left(\mathrm{m}^{3}\right)$;

$\partial \Phi:$ A quantity describing the state of the system $\left(\mathrm{W} / \mathrm{m}^{2}\right)$;

$\partial x$ : Material thickness (m);

$A$ : The flow boundary surface (control surface) $\left(\mathrm{m}^{2}\right)$;

$$
F_{\text {int }}, F_{\text {out }} \text { : Internal and external flux }\left(\mathrm{W} / \mathrm{m}^{2}\right) \text {. }
$$

\subsection{Modeling the Climate of the Greenhouse Systems}

\subsubsection{Cooling Pad Model}

In a greenhouse, evaporative cooling devices are used to reduce the temperature when the fan cannot reach appropriate levels for optimal plant growth. In equipped greenhouses, cooling evaporation is the second part of the unrealized gain. Most evaporative cooling methods can be modeled as adiabatic cooling process; the minimum temperature and the achievable maximum vapor pressure is equal to the wet bulb.

The effectiveness of the typical tablet is about $85 \%$. The heat loss rate depends on the fan speed.

$$
\begin{aligned}
& H_{\text {pad }}=H_{\text {out }+\eta_{\text {pad }}}\left(H_{w b}-H_{\text {out }}\right) \\
& T_{\text {pad }}=T_{\text {out }-\eta_{\text {pad }}}\left(T_{w b}-T_{\text {out }}\right) \\
& \mathcal{Q}_{\text {pad }}=\rho \dot{V} F a n C_{P} \eta_{\text {pad }}\left(T_{\text {out }}-T_{w b}\right)
\end{aligned}
$$

$\eta_{\text {pad }}:$ Pad efficiency;

$T_{\text {out }}, T_{w b}$ : The difference between the outside temperature and wet bulb (K);

$C_{P}:$ Specific heat (J/kg.k);

$\rho$ : Density $\left(\mathrm{kg} / \mathrm{m}^{3}\right)$;

$\dot{V}$ : Fan speed $(\mathrm{m} / \mathrm{s})$.

\subsubsection{Model of Fogging System}

The flow of steam and heat are determined through Ohm's Law and are as following:

$$
\begin{gathered}
\dot{e}=K A_{n e t}\left(V P_{s a t}\left(T_{w b}\left[T_{\text {air }}, r h_{\text {air }}\right]\right)-V P_{\text {air }}\right) \\
q=\lambda \dot{e}
\end{gathered}
$$

$q$ : The heat transfer between the nebulizer and the air of agricultural greenhouse $\left(\mathrm{W} / \mathrm{m}^{2}\right)$;

$\mathrm{K}$ : Global coefficient of heat transmission $\left(\mathrm{W} / \mathrm{m}^{2} \cdot \mathrm{k}\right)$; 
$P_{\text {sat }}:$ Saturation pressure (Pascale);

$P_{\text {air }}$ : Pression de l'air ambiant (pascale);

$\lambda$ : Thermal conductivity $\left(\mathrm{W} / \mathrm{m}^{2} . \mathrm{k}\right)$.

2.2.3 Evaluation Model of the Wall Temperature $\mathrm{T}_{\mathrm{p}}$

The $\mathrm{T}_{\mathrm{p}}$ wall temperature evaluation model, closest to reality is determined based on the average temperatures $T_{p_{i}}$ and $T_{p_{e}}$

$$
T_{p}=\frac{T_{p_{i}}+T_{p_{e}}}{2}
$$

The indoor and outdoor temperatures $T_{p_{i}}$ and $T_{p_{e}}$ are:

$$
\begin{array}{r}
T_{p_{i}}=T_{a i r, i}-\frac{K\left(T_{a i r, i}-T_{a i r, e}\right)}{h_{p_{i}}} \\
T_{p_{e}}=T_{a i r, e}+\frac{K\left(T_{a i r, i}-T_{a i r, e}\right)}{h_{p_{e}}}
\end{array}
$$

The temperature evaluation model of $\mathrm{T}_{\mathrm{p}}$ wall will be expressed:

$$
\begin{gathered}
T_{p}=\frac{T_{a i r, i}+T_{a i r, e}}{2}+\frac{k\left(h_{p_{i}}-h_{p_{e}}\right)}{h_{p_{i}} \cdot h_{p_{e}}} \cdot \frac{T_{a i r, i}-T_{a i r, e}}{2} \\
T_{p}=\frac{T_{a i r, i}+T_{a i r, e}}{2}+C_{B} \frac{T_{a i r, i}-T_{a i r, e}}{2}
\end{gathered}
$$

where: $\quad C_{B}=\frac{\lambda\left(h_{p_{i}}-h_{p_{e}}\right)}{\lambda\left(h_{p_{i}}+h_{p_{e}}\right)+e h_{p_{i}} \cdot h_{p_{e}}}$

$T_{\text {air }, i}, T_{\text {air }, e}$ : Dry Air temperature Inside/Outside (K);

$h_{p_{i}}, h_{p_{e}}$ : Coefficient of superficial exchanges at the inter wall, of the outer wall $\left(\mathrm{W} / \mathrm{m}^{2} . \mathrm{k}\right)$;

$C_{B}$ : Quotient de BIBI(.).

This report dimensionless $C_{B}$ is used in evaluating the $\mathrm{T}_{\mathrm{p}}$ wall temperature, it is now called the quotient of BIBI, which is the ratio of the difference of surface thermal exchange by conduction, convection and radiation occurring at the level of the greenhouse coverage.

\subsubsection{Heating System}

The heat produced per unit of fuel is modeled as:

$$
\begin{gathered}
h_{\begin{array}{c}
\text { combution } \\
\text { sensible }
\end{array}}=L H V+\ldots \\
\lambda \phi *\left[\frac{36}{16} \phi^{-1}-e_{\text {sat }}\left(T_{\text {exhaust }}\right)\right] \ldots \\
-(1-r) C_{P, \text { air }} T_{\text {exhaust }}
\end{gathered}
$$

$h_{\text {combution }}$ : Sensible heat load of a condensing sensible

water heater $(\mathrm{J})$;

$L H V$ : Lower heating value $(\mathrm{KJ} / \mathrm{kg})$;

$\Phi$ : The fuel air;

36/16: The weight ratio of the produced steam to supply the burner;

$T_{\text {exhaust }}$ : The temperature of the exhaust gas (k);

$r$ : The return ratio.

\subsection{Energy Balance of the Greenhouse}

The analytical energy balance equation of the greenhouse:

Stored energy change $=$ Gain from internal sources+ Gain from the sun - Losses due to conduction through the cover - Losses due to long wave radiation - Unrealized losses (evaporation) Losses due to the exchange of air .

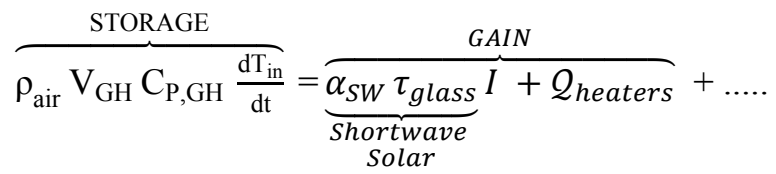

$$
\begin{aligned}
& \text { GAIN } \\
& +\underbrace{\overbrace{r_{\text {conv }, \text { out }}+r_{\text {cond,cover }}+r_{\text {cond,cover }}+r_{\text {conv }, \text { out }}}^{r_{\text {cond }} A_{\text {cover }}\left[V P_{\text {in }}-V P_{\text {sat }}\left(T_{\text {cover }}\right)\right]} \ldots-}_{\text {Condensation }} \\
& \overbrace{\underbrace{\overbrace{r, s k y}\left(1-\varepsilon_{\text {cover }}\right)\left(T_{\text {in }}-T_{\text {sky }}\right)-08 \varepsilon_{\text {cover }} h_{r, \text { cver }}\left(T_{\text {in }}-T_{\text {cover }}\right)}_{\text {longwave }}}^{\text {LOSSES }} \cdots
\end{aligned}
$$




$$
\begin{aligned}
& \text { LOSSES }
\end{aligned}
$$

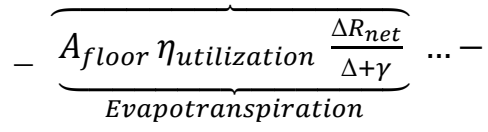

$$
\begin{aligned}
& \text { LOSSES CONT }
\end{aligned}
$$

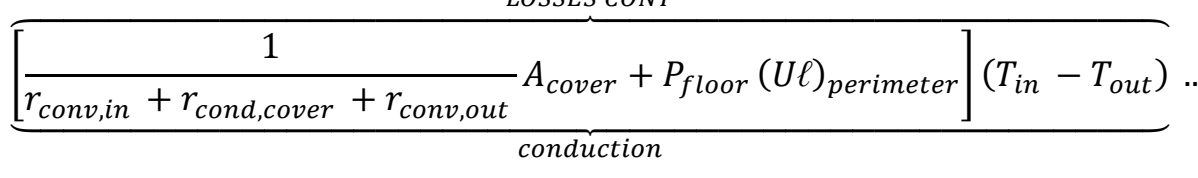

$$
\begin{aligned}
& \ldots .-\overbrace{\underbrace{\lambda \mathrm{K}_{\text {net }}\left(V P_{\text {sat }}\left(T_{\text {wb }}\left[T_{\text {air }}, r h_{\text {air }}\right]\right)-V P_{\text {air }}\right)}_{\text {Foggers }}}^{\text {LOSSES CoN }} \ldots- \\
& \text { LOSSES CON } \\
& \underbrace{\underbrace{}_{\left.\rho C_{(P, \text { air })} \dot{V}_{\text {inf }}\left(T_{\text {in }}-T_{\text {out }}\right)-\rho C_{(P, \text { air }}\right)} \dot{V}_{\text {net }}\left(T_{\text {in }}-T_{\text {pad }}\right)}_{\text {advection }}
\end{aligned}
$$

$e_{s a t}$ : Indicates the report saturated with the relative humidity in the sub-model of combustion ( $\mathrm{Kg}$ steam $/ \mathrm{kg}$ air); $\mathcal{Q}_{\text {heaters }}$ : The heat provided by the heating system $(\mathrm{W})$;

$r_{\text {conv,in }}, r_{\text {conv,out }}$ : Heat transfer coefficient inside and outside by convection $\left(\mathrm{W} / \mathrm{m}^{2} . \mathrm{k}\right)$.

\subsection{The Mass Transfer in the Greenhouse}

The mass balance for moisture in the greenhouse can be written as following Eq. (11):

$$
\begin{aligned}
\rho_{\text {air }} V_{\text {greenhouse }} & \frac{d e_{\text {in }}}{d t} \\
& =-\dot{V}_{\text {inf }} * \rho_{\text {air }}\left(H_{\text {in }}-H_{\text {out }}\right)-\dot{V}_{\text {vent }} * \rho_{\text {air }}\left(H_{\text {in }}-H_{\text {pad }}\right)+\underbrace{\frac{1}{\lambda} A_{\text {floor }} \eta_{\text {uilization }} \frac{\Delta R_{\text {net }}}{\Delta+\gamma}}_{\text {Evapotranspiration }} \\
& -\underbrace{K_{\text {cond }} A_{\text {cover }}\left[V P_{\text {in }}-V P_{\text {sat }}\left(T_{\text {cover }}\right)\right]}_{\text {condensation }}+\underbrace{K A_{\text {net }}\left(V P_{\text {sat }}\left(T_{\text {wb }}\left[T_{\text {air }} r h_{\text {air }}\right]\right)-V P_{\text {air }}\right)}_{\text {foggers }} \\
& +\underbrace{r \phi e_{\text {sat }}\left(T_{\text {exhaust }}\right) \frac{Q_{\text {heat }}}{h_{\text {combustion }}}}_{\text {combustion }}
\end{aligned}
$$

$\dot{V}_{\text {inf }}:$ The speed of air infiltration $(\mathrm{m} / \mathrm{s})$;

$V_{\text {greenhouse }}$ : The total volume of agricultural greenhouse $\left(\mathrm{m}^{3}\right)$;

$H_{\text {in }}, H_{\text {out }}:$ The indoor and outdoor humidity $(\mathrm{KJ} / \mathrm{kg})$;

$\dot{V}_{\text {vent }}$ : Ventilation rate $\left(\mathrm{m}^{3}\right.$ air/s);

And for the humidity balance:

Rates of change in absolute humidity $=$ Infiltration

+ Ventilation * (humidity difference with the outside)

+ Misting + Cooling + AND - Condensation.

The status of humidity function is Eq. (12):

$$
\begin{aligned}
& \frac{d H_{\text {in }}}{d t} \underbrace{=-n V_{p}\left(H_{\text {in }}-H_{\text {sat }}\right)}_{\text {Ventilation infiltration }}+K_{\text {foggers }}\left(V P_{\text {in }}-\right. \\
& \left.V P_{\text {sat,wetbulb }}\right)-K_{\text {condensation }}\left(V P-V P_{\text {sat }}\right)+ \\
& \underbrace{E}_{\text {Evapotranspiration }}
\end{aligned}
$$

$\underbrace{E}_{\text {E }} \quad$ : The amount of heat provided Evapotranspiration

by evapotranspiration (W).

Mass balance for $\mathrm{CO}_{2}$ is Eq. (13): 


$$
\begin{gathered}
\rho_{\text {air }} V_{\text {greenhouse }} \frac{100}{29} \frac{d C_{c 0_{2} \text { in }}}{d t} \\
=-\rho_{\text {air }} \frac{100}{29}\left(\dot{V}_{\text {inf }}+\dot{V}_{\text {vent }}\right)\left(C_{c 0_{2} \text { in }} C_{c 0_{2} \text { out }}\right) \\
+-\dot{F}_{\text {photosynthesis }}+\underbrace{r \zeta \frac{100}{M W_{\text {fuel }}} \frac{Q_{\text {heat }}}{h_{\text {combution }}}}_{\text {combustion }}
\end{gathered}
$$

$\mathrm{CO}_{2}$ Mass Balance in molar units (ppm or $\mu \mathrm{mol}$ $\mathrm{CO}_{2}$ per mol air).

$\zeta$ : The number of moles of carbon per mole of fuel; $\dot{V}_{\text {inf }}$ : Ventilation rate $\left(\mathrm{m}^{3} \mathrm{air} / \mathrm{s}\right)$;

$\dot{F}_{\text {photosynthesis }}$ : The amount of heat supplied by photosynthesis (W).

\subsection{Photosynthesis}

Photosynthesis is a complex process. $\mathrm{CO}_{2}$ fixation and subsequent conversion into carbohydrates are not a single reaction, but a series of steps, the Calvin cycle (see Fig. 1) [11].

According to Farquhar model, the $\mathrm{CO}_{2}$ compensation model is:

$$
P=\left(1-\frac{\Gamma}{C_{i}}\right) * \min \left\{W_{c}, W_{j}\right\}
$$

Farquhar model with $\Gamma, \mathrm{CO}_{2}$ compensation point.

$C_{i}$ : Internal CO2 concentration (ppm).

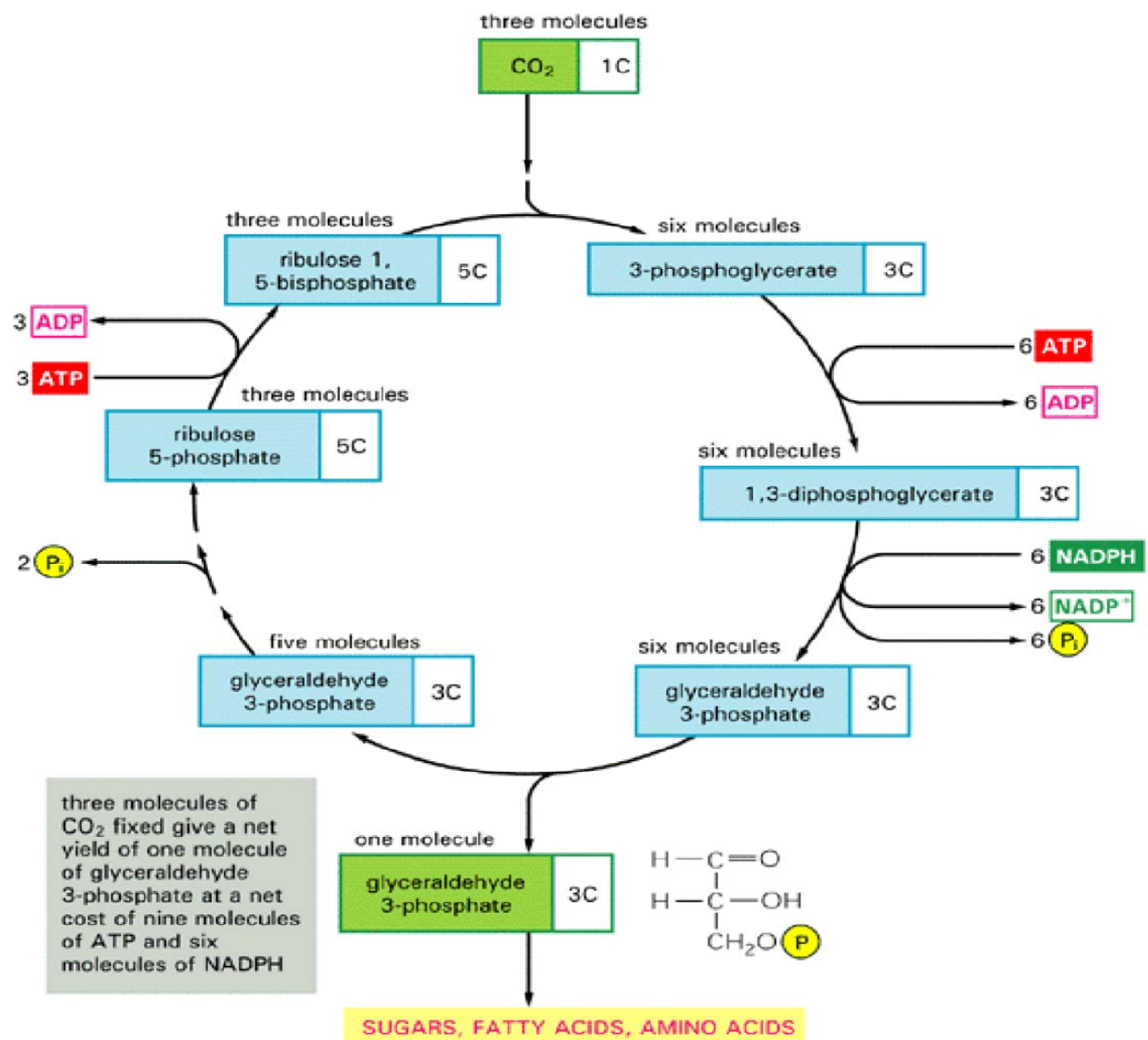

Fig. 1 Schematic Calvin cycle. The reaction at the apex $\left(\mathrm{CO}_{2}\right.$ fixation and RuBP) is catalyzed by the enzyme Rubisco. This reaction ordered carbon assimilation rates, and that is modeled by Farquhar. al. equations. Source: Cellupedia, Calvin cycle. 


\subsection{Plant State of Water Balance}

$$
C_{P L A N T} \frac{d \psi_{\text {plant }}}{d t}=\frac{\left(\psi_{\text {soil }}-\psi_{\text {plant }}\right)}{R_{\text {root }} A_{\text {root }}}-E
$$

In the model of GUESS, we assume that the soil is well watered, so that the physiological effects of the state of water should be minimal, except in stomata.

$\psi$ : The potential of water;

$C_{P L A N T}$ : The capacity of the plant $\left(\right.$ mole* $\left.^{2}\right)$;

$E$ : Evapotranspiration;

$A_{\text {root }}$ : The root surface $\left(\mathrm{m}^{2}\right)$;

$R_{\text {root }}$ : The growth rate.

\subsection{Stomatal Conductance and Balance $\mathrm{CO}_{2}$}

The rate of photosynthesis in the Farquhar model depends on the internal concentration of $\mathrm{CO}_{2}$.

To determine the concentration of $\mathrm{CO}_{2}$, a mass balance is performed on the sheet.

$$
C_{\text {leaf }} \frac{d\left[\mathrm{Co}_{2}\right]_{i}}{d t}=\frac{\left(\left[\mathrm{CO}_{2}\right]_{e}-\left[\mathrm{CO}_{2}\right]_{i}\right)-P_{\text {net }}}{\frac{1}{g_{\text {stomatal }}}+\frac{1}{g_{\text {aerodynamic }}}}
$$

According to GUESS the plant stomatal equation of is:

$$
\begin{array}{r}
g_{\text {stomatal }}=\min \\
\left\{g_{\text {closed }+m}\left(\frac{r h_{\text {leaf }} P_{\text {net }}}{\left[C O_{2}\right]_{\text {leaf }}}\right)\right. \\
\left.*\left(\frac{\theta_{\text {soil }}-\theta_{W P}}{\theta_{F C}-\theta_{W P}}\right), g_{\text {open }}\right\}
\end{array}
$$

Ball-Berry modified model used in GUESS Eq. (17).

$g_{\text {stomatal }}$ : Stomatal conductance in units of $\left(\right.$ mole. $\left.s^{-1} \cdot m^{-2}\right)$.

\section{Fuzzy Sets}

The input variables in a fuzzy control system are generally mapped by sets of membership functions similar to it, called "fuzzy set". The process of converting a crisp input value to a fuzzy value is called "fuzzy logic". A control system may also have different types of switch, or "ON-OFF", inputs and analog inputs and during switching inputs will always be a truth value of 1 or 0 , but the system can handle as simplified fuzzy functions happen to be one value or another. Given "mappings" of input variables membership functions and truth values, the microcontroller then makes decisions for action on the basis of a set of "rules".

\subsection{Membership Functions}

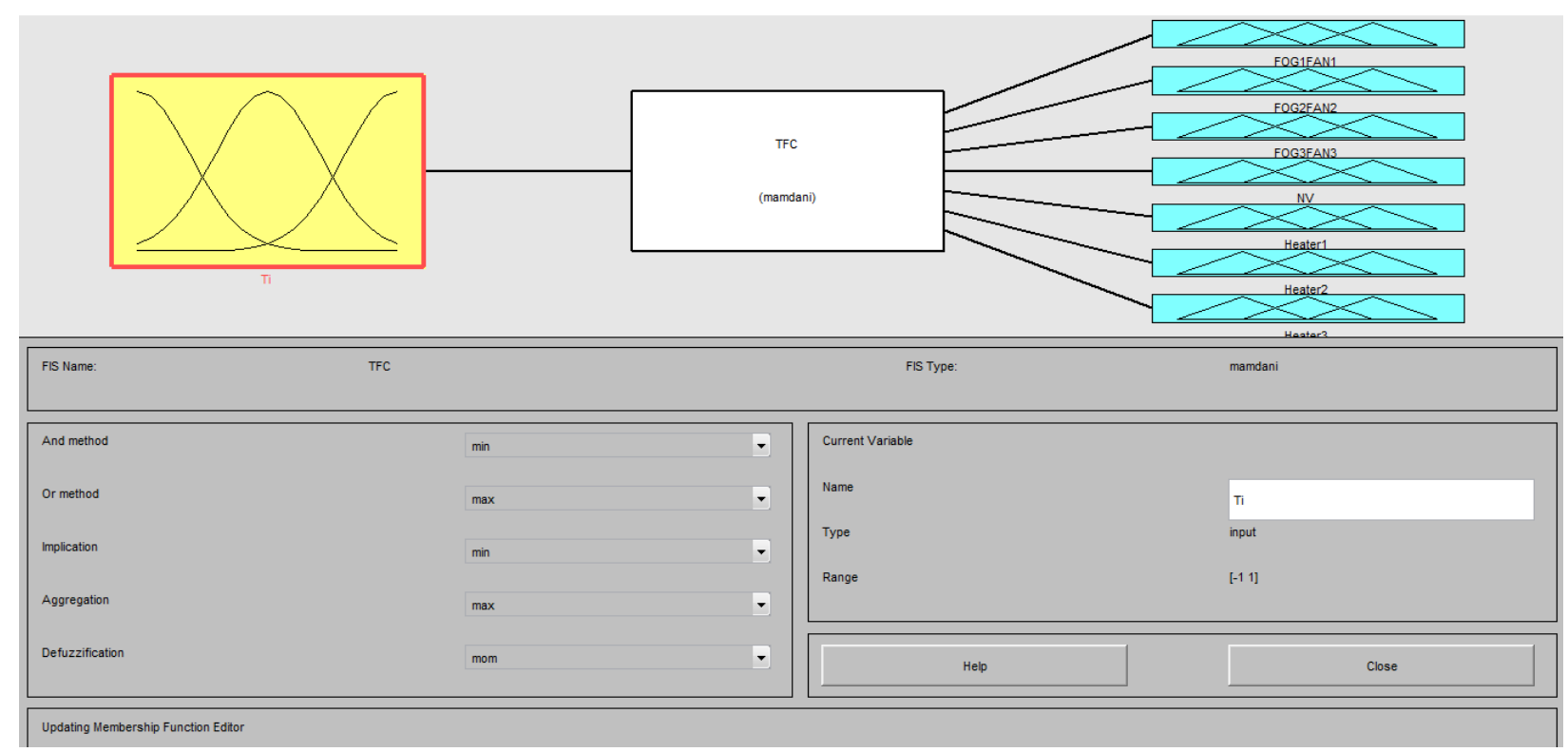




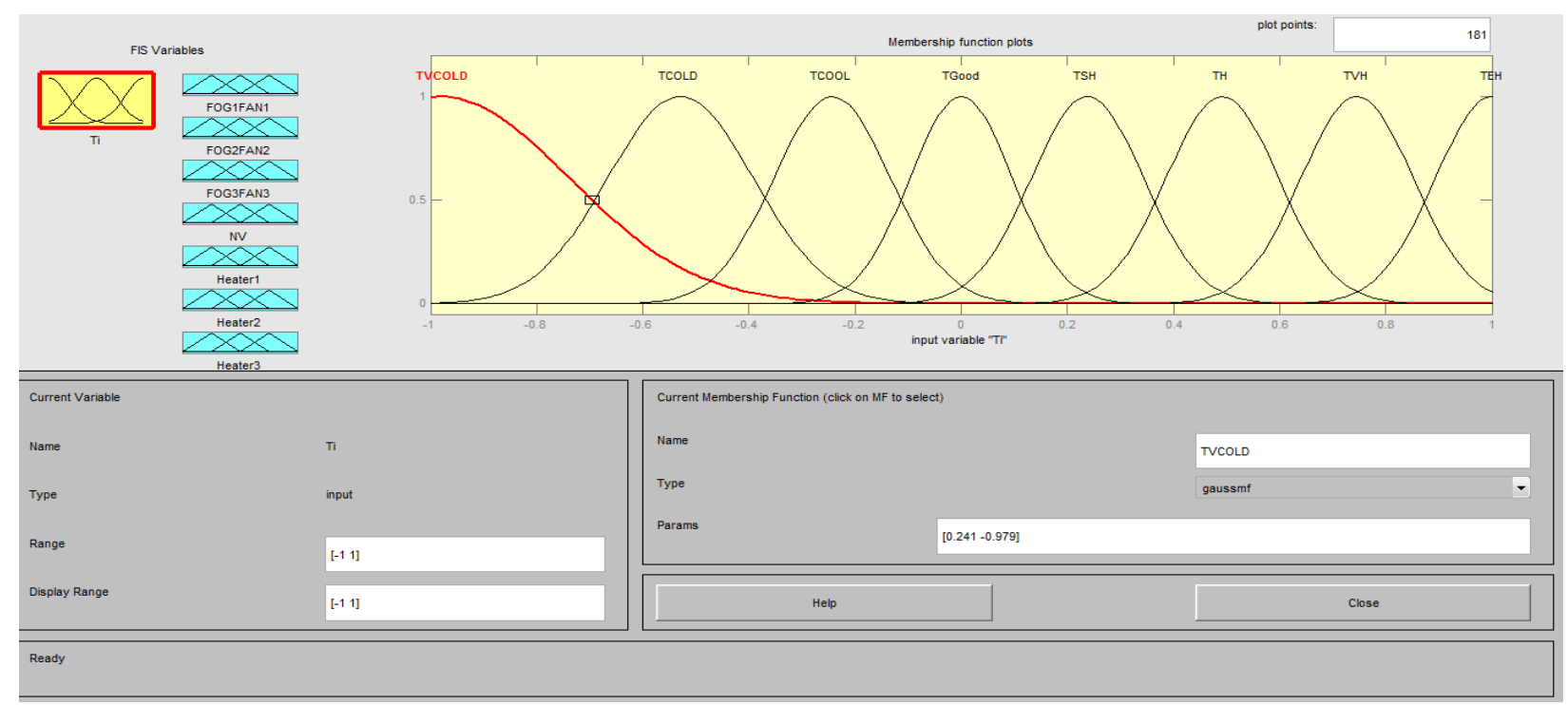

Fig. 2 Representation rules of membership.

\subsection{Rules of Decisions}

- If (Ti is TVCOLD) then (FOG1FAN1 is OFF)(FOG2FAN2 is OFF)(FOG3FAN3 is OFF)(NV is $\mathrm{OFF})($ Heater1 is $\mathrm{ON})($ Heater2 is $\mathrm{ON})($ Heater3 is ON) (1)

- If ( $\mathrm{Ti}$ is TCOLD) then (FOG1FAN1 is OFF)(FOG2FAN2 is OFF)(FOG3FAN3 is OFF)(NV is $\mathrm{OFF})($ Heater1 is $\mathrm{ON})($ Heater2 is $\mathrm{ON})($ Heater3 is OFF) (1)

- If ( $\mathrm{Ti}$ is TCOOL) then (FOG1FAN1 is OFF)(FOG2FAN2 is OFF)(FOG3FAN3 is OFF)(NV is $\mathrm{OFF})($ Heater1 is $\mathrm{ON})($ Heater2 is $\mathrm{OFF})($ Heater3 is OFF) (1)

- If ( $\mathrm{Ti}$ is TSH) then (FOG1FAN1 is OFF)(FOG2FAN2 is OFF)(FOG3FAN3 is OFF)(NV is $\mathrm{ON})($ Heater1 is $\mathrm{OFF})($ Heater2 is $\mathrm{OFF})($ Heater3 is OFF) (1)

- If ( $\mathrm{Ti}$ is $\mathrm{TH}$ ) then (FOG1FAN1 is $\mathrm{ON})(\mathrm{FOG} 2 \mathrm{FAN} 2$ is OFF)(FOG3FAN3 is OFF)(NV is OFF)(Heater1 is OFF)(Heater2 is OFF)(Heater3 is OFF) (1)

- If ( $\mathrm{Ti}$ is TVH) then (FOG1FAN1 is $\mathrm{ON})(\mathrm{FOG} 2 \mathrm{FAN} 2$ is $\mathrm{ON})(\mathrm{FOG} 3 \mathrm{FAN} 3$ is $\mathrm{OFF})(\mathrm{NV}$ is OFF)(Heater1 is OFF)(Heater2 is OFF)(Heater3 is OFF) (1)

- If ( $\mathrm{Ti}$ is TEH) then (FOG1FAN1 is $\mathrm{ON})(\mathrm{FOG} 2 \mathrm{FAN} 2$ is $\mathrm{ON})(\mathrm{FOG} 3 \mathrm{FAN} 3$ is $\mathrm{ON})(\mathrm{NV}$ is
OFF)(Heater1 is OFF)(Heater2 is OFF)(Heater3 is OFF) (1)

\section{Simulation and Model Validation}

Our model is based on the greenhouse GUESS model that is set for a multi greenhouse chapel which each module is $8.5 \mathrm{~m}$ wide, $34 \mathrm{~m}$ deep and ridge height of $4.5 \mathrm{~m}$. Infiltration rate is 1.1 air changes per hour, and a $\mathrm{U}$ value of $5.76 \mathrm{~W} / \mathrm{m}^{2} . \mathrm{K}$ was used. The model of the plant was set for Douglas seedling plants which were started at $0.57 \mathrm{~g}$ dry weight, and harvested $1.67 \mathrm{~g}$ dry weight; a new growing season was recorded at harvest.

A set of hourly data for 2015 (1 January to 31 December) weather station of Biskra Algeria, was used to validate our model as a CSV file that consists of four columns (global solar radiation, temperature, humidity and wind speed).

The model of the greenhouse was coded using the full version of Windows MATLAB R2012b (8.0.0.783), 64bit (win64) with Simulink. The simulation was performed on a Toshiba laptop. The laptop is equipped with a hard drive $700 \mathrm{~GB}$ and $5 \mathrm{~GB}$ of RAM. Simulink model of the parties was made in "Accelerator" mode that has first generated a compact representation of Code $\mathrm{C}$ of the diagram, then compiled and executed. 


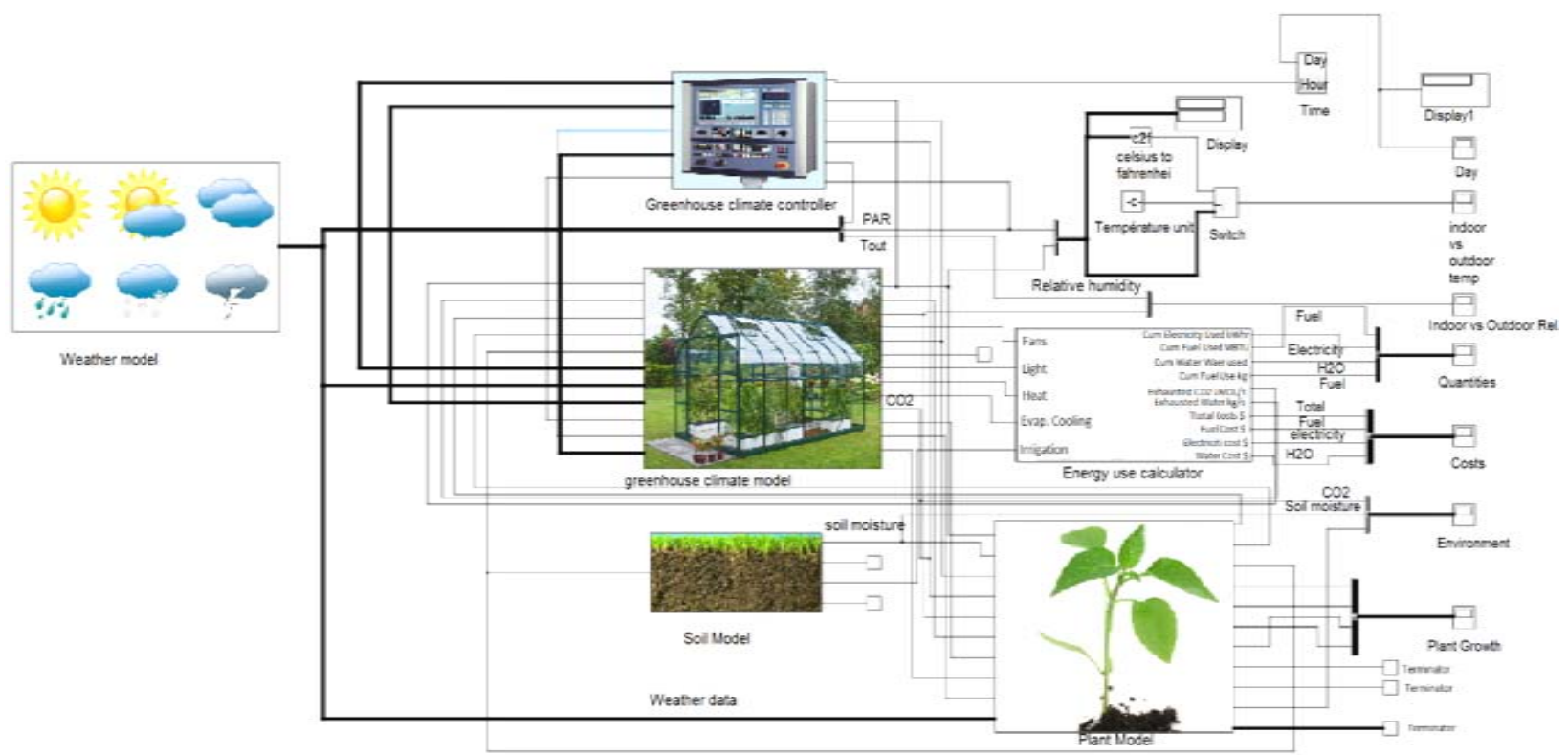

Fig. 3 Simulink representation of the global greenhouse model. 


\subsection{Greenhouse Climate Model}

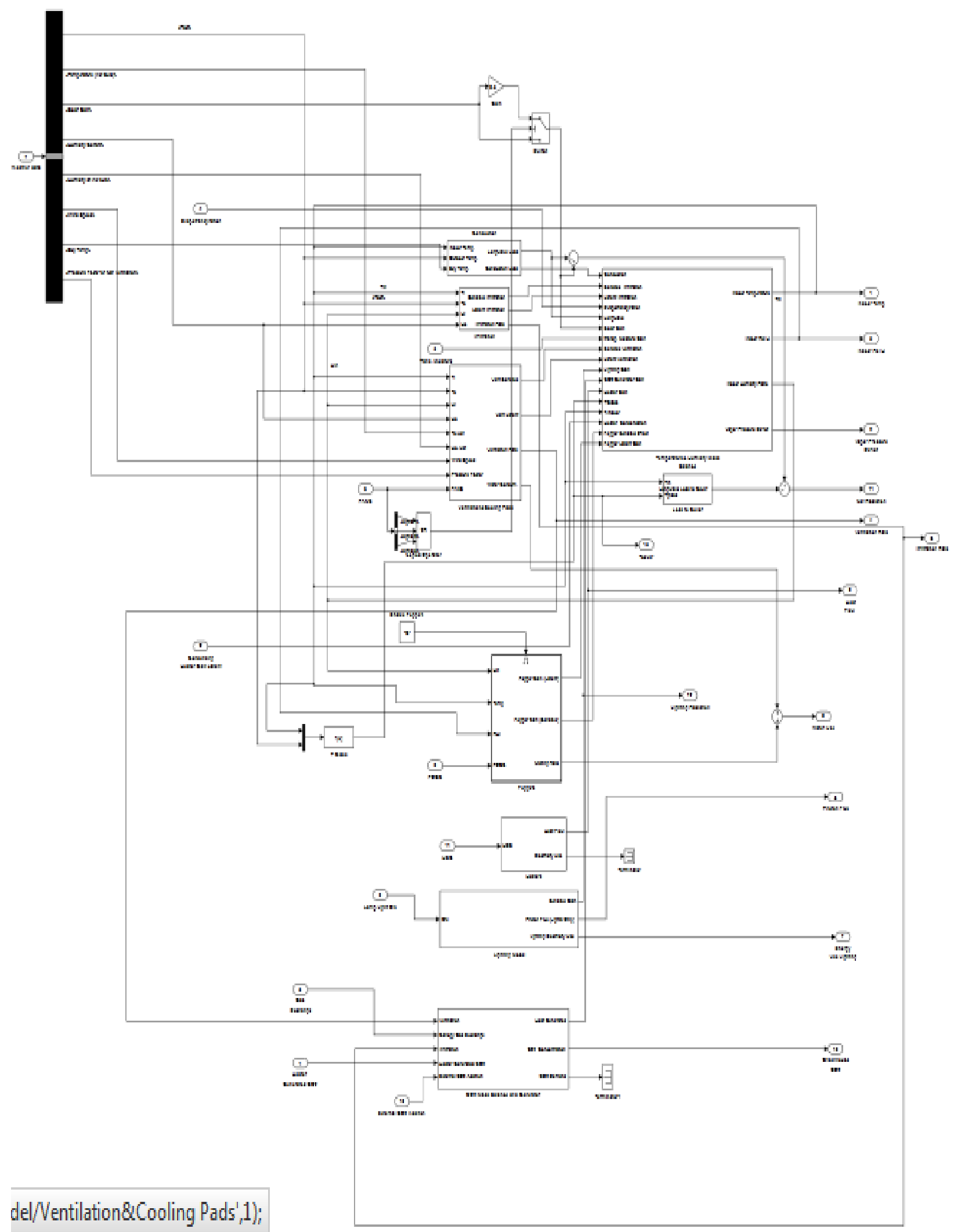

Fig. 4 Simulink representation of the greenhouse climate model. 
4.3 Fuzzy Logic Controller Simulation Model of the Greenhouse

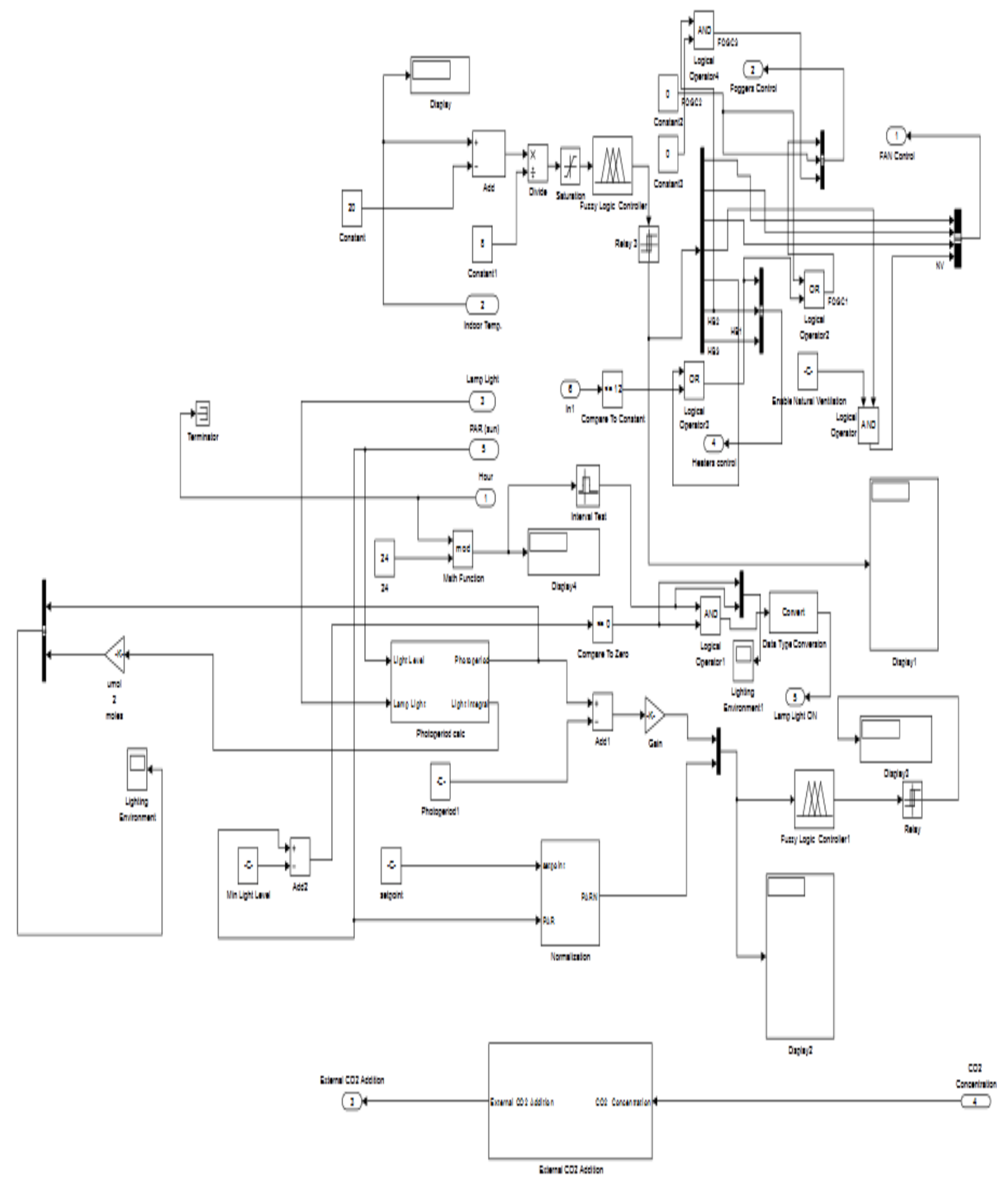

Fig. 5 Simulink representation of the fuzzy logic controller model. 


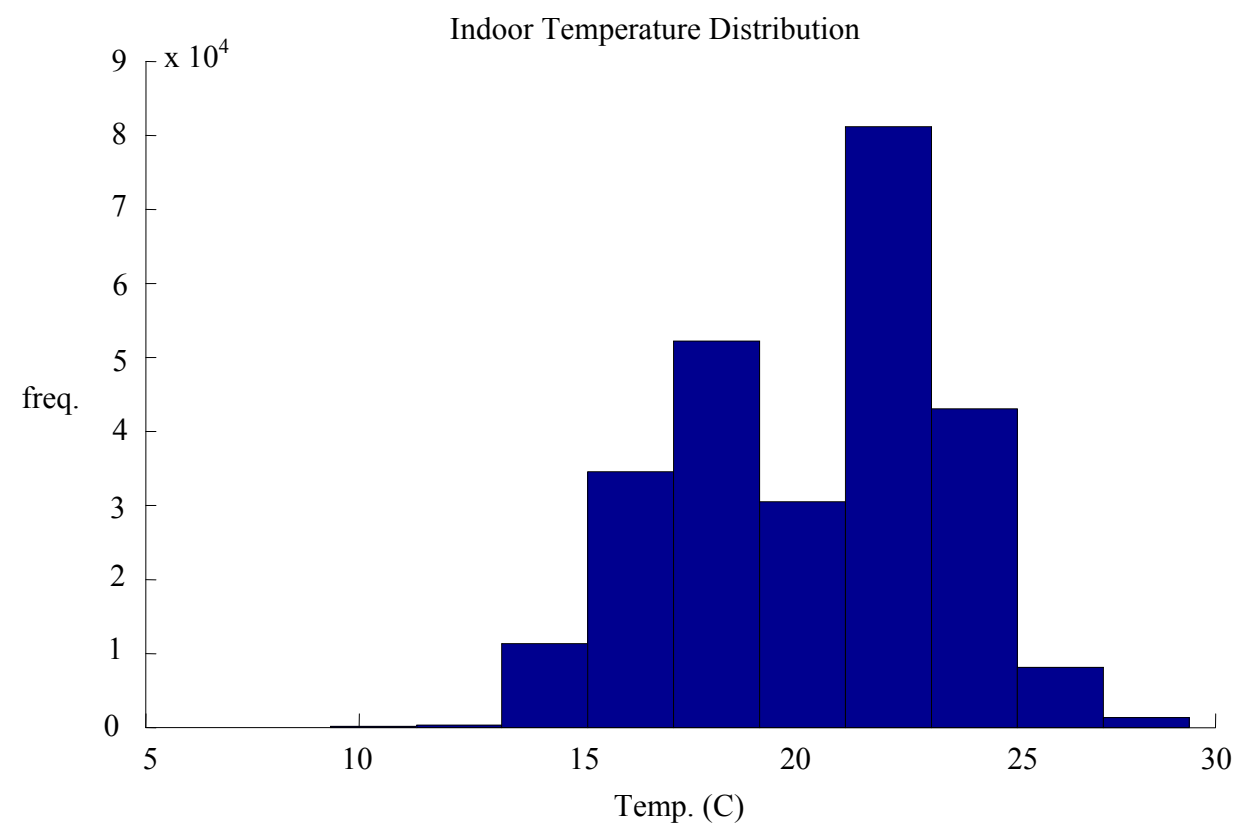

Fig. 6 Histogram shows the distribution of indoor temperature.
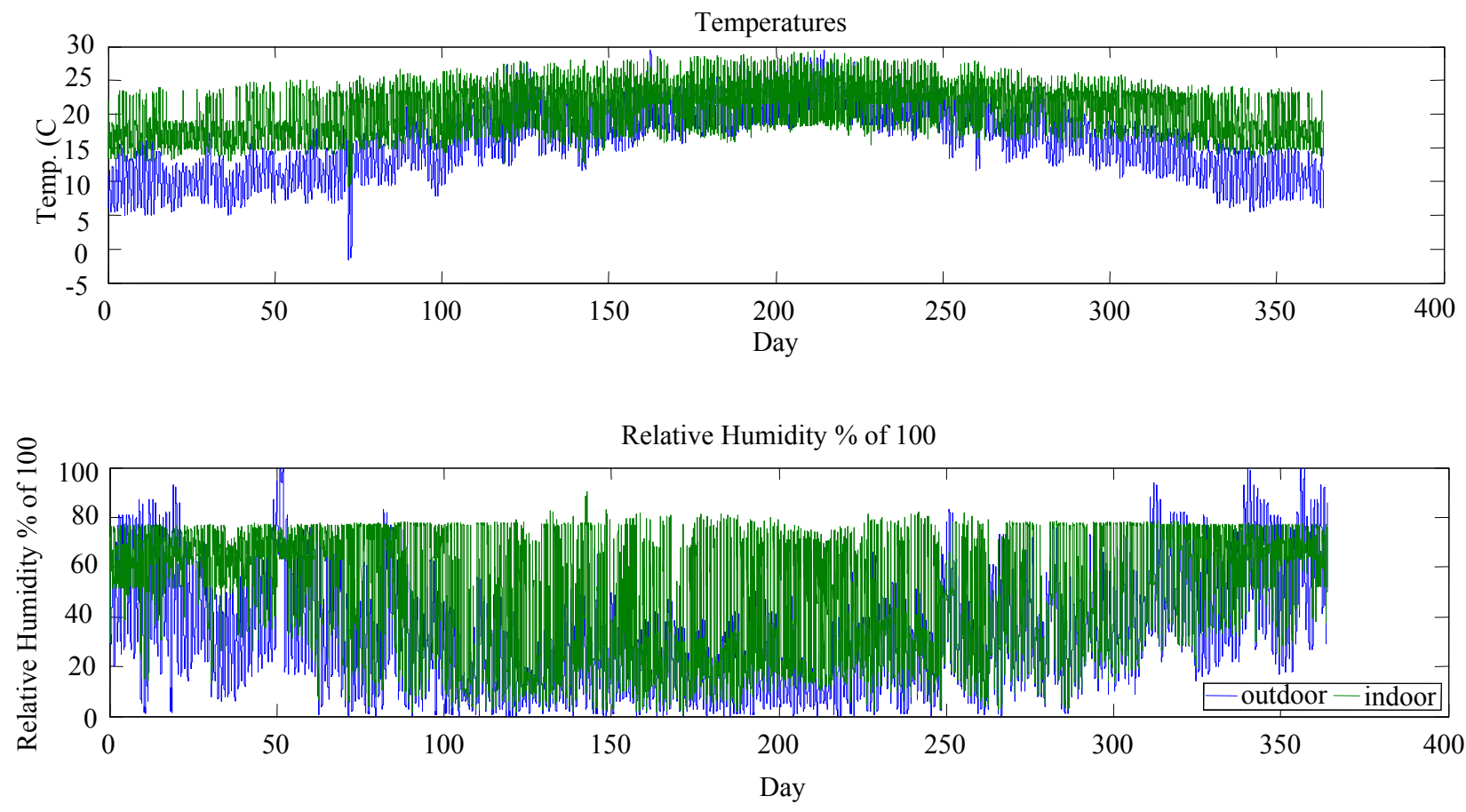

Fig. 7 The evolution of humidity and temperature (interior/exterior).

\section{Results}

The simulation results clearly visualize the actual thermo-energy behavior of agricultural greenhouse, applying the model of artificial intelligence, namely the application of fuzzy logic in arid region [12].
It is found that most of the internal temperature values are in the range of $15{ }^{\circ} \mathrm{C}$ to $25{ }^{\circ} \mathrm{C}$ for the autumn winter period, and in the range $20^{\circ} \mathrm{C}$ to $28^{\circ} \mathrm{C}$ for the spring summer period in a large variation the temperature during the winter autumn period is due to heat loss during the night, clearing heating is 
insufficient and expensive for this improved thermal insulation of the covering wall is necessary.

The improved thermal insulation of the cover may be carried out in practice by the addition of a plastic air bubble layer mounted to the inside wall face.

During the period of spring-summer the temperature is almost within the desired range except for half of the summer where the temperature is a little increase. The use of cooling systems and spray is necessary to lower the temperature in the interval longed for.

But this solution is insufficient and really expensive, for this purpose we should improve the characteristics of the coverage of the agricultural greenhouse for example thermal insulation or blanket double wall which demonstrates improved efficiency of heating, cooling, etc.

The relative humidity generally stays close to the optimum for all the year except in summer when the humidity drops below threshold due to significant vaporization used for temperature compensation, to resolve this problem adding a screen on the roof of the greenhouse and improving irrigation can compensate the lack of relative humidity in the arid region.

\section{Conclusions}

However, our objective is achieved to the extent that it has been shown through modeling and control by the use of fuzzy logic, this area is very difficult because it is a multi control variable which the greenhouse is a biophysical system where parameters are highly correlated as shown by the results. This technique of fuzzy logic has been adapted to the greenhouse to a promising future for the climate control and management of the greenhouse. For greenhouse growers, it is a preferred approach for structuring and knowledge aggregation and as a means of identification of gaps in the understanding of mechanisms and interactions that occur in the system-greenhouse.

Fuzzy logic is a branch of artificial intelligence, which must point out its advantages and disadvantages. Its use has led to quite satisfactory results of the control and regulation perspective.

We remain optimistic in the near future, as to the operation of artificial intelligence, including the use of fuzzy logic which indicates:

- For the control and regulation of the greenhouse microclimate;

- By the conservation of energy;

- For the efficiency of energy use in the greenhouses operation;

- For improved productivity of crops under greenhouses;

- In a significant reduction of human intervention.

\section{Acknowledgement}

This research was supported/partially supported by N. Bibi-Triki, B. Draoui, and A. Abène. I thank our colleagues who provided insight and expertise that greatly assisted the research and we thank "anonymous" reviewers for their so-called insights.

\section{References}

[1] Bendimerad, S., Mahdjoub, T., Bibi-Triki, N., Bessenouci, M. Z., Draoui, B., and Bechar, H. 2014. "Simulation and Interpretation of the BIBI Ratio $\mathrm{C}_{\mathrm{B}}($.$) , as a Function of$ Thermal Parameters of the Low Inertia Polyethylene Wall of Greenhouses." Physics Procedia 55: 157-64. DOI: 10.1016/j.phpro.2014.07.023.

[2] Bibi-Triki, N., Bendimemerad, S., Chermitti, A., Mahdjoub, T., Draoui, B. et al. 2011. "Modeling, Characterization and Analysis of the Dynamic Behavior of Heat Transfers through Polyethylene and Glass Walls of Greenhouses." Physics Procedia 21: 67-74. DOI: 10.1016/j.phpro.2011.10.011.

[3] Faouzi Didi, Bibi Triki, N., and Chermitti, A. 2016. "Optimizing the Greenhouse Micro-climate Management by the Introduction of Artificial Intelligence Using Fuzzy Logic.” Int. J. Computer Eng. Technology 7 (3): 78-92. May-June 2016. Article ID: IJCET_07_03_007.

[4] Abdelhafid, H., Draoui, B., Boulard, T., Taibi, R., and Hezzab, A. 2008. "Evolutionary Algorithms in the Optimization of Greenhouse Climate Model Parameters." Int. Rev. Comput. Software.

[5] Draoui, B., Bounaama, F., Boulard, T., and Bibi-Triki, N. 2013. "In-situ Modelisation of a Greenhouse Climate 
Including Sensible Heat, Water Vapour and $\mathrm{CO}_{2}$ Balances." EPS Web Conferences 45: 01023. DOI: 10.1051/epjconf/20134501023.

[6] Hasni, A., Draoui, B., Boulard, T., Taibi, R., and Dennai, B. 2009. "A Particle Swarm Optimization of Natural Ventilation Parameters in a Greenhouse with Continuous Roof Vents." Sensor Transducers J. 102: 84-93.

[7] El Aoud, M. M., and Maher, M. 2014. "Intelligent Control for a Greenhouse Climate." Int. J. Advances Eng. Technology 7: 1191-205. http://www.e-ijaet.org/media/8I22-IJAET0722618_v7_is s4_1191-1205.pdf.

[8] Bouaama, F., Lammari, K., and Draoui, B. 2008. "Greenhouse Air Temperature Control Using Fuzzy
PID $+\mathrm{I}$ and Neuron Fuzzy Hybrid System Controller." In Proceedings of the International Review of Automatic Control (IRE.A.CO).

[9] Dhamakale, S. D., and Patil, S. B. 2011. "Fuzzy Logic Approach with Microcontroller for Climate Controlling in Green House.” Int. J. Emerg. Technol. 2: 17-9.

[10] https://ecommons.cornell.edu/handle/1813/3437.

[11] http://crawl.prod.proquest.com.s3.amazonaws.com/fpcac he/e21ce074acc4e7cb8522f701860717eb.pdf?AWSAcces sKeyId=AKIAJF7V7KNV2KKY2NUQ\&Expires $=14720$ 19266\&Signature=DtN3iZHV1 iewwrj\%2FPSvxzwEq3nI $\% 3 \mathrm{D}$.

[12] http://www.wunderground.com/cgibin/findweather/getFo recast?qery ${ }^{2}$. 
Appendix: Plant growth caracteristics

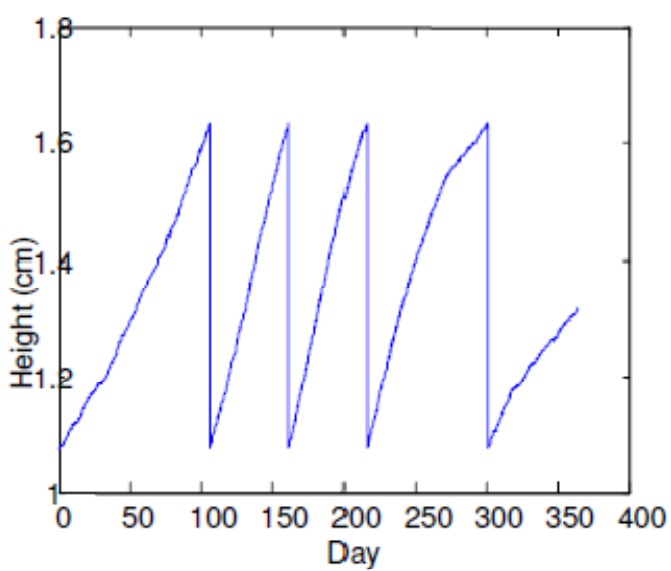

figure 1

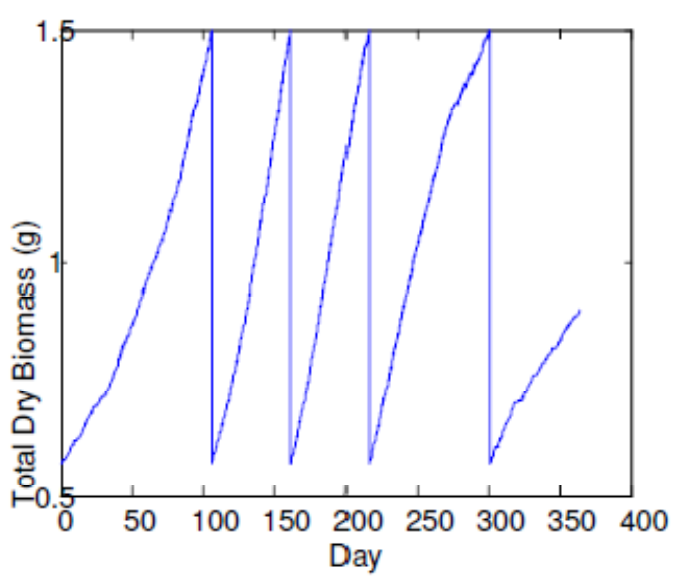

Figure 3

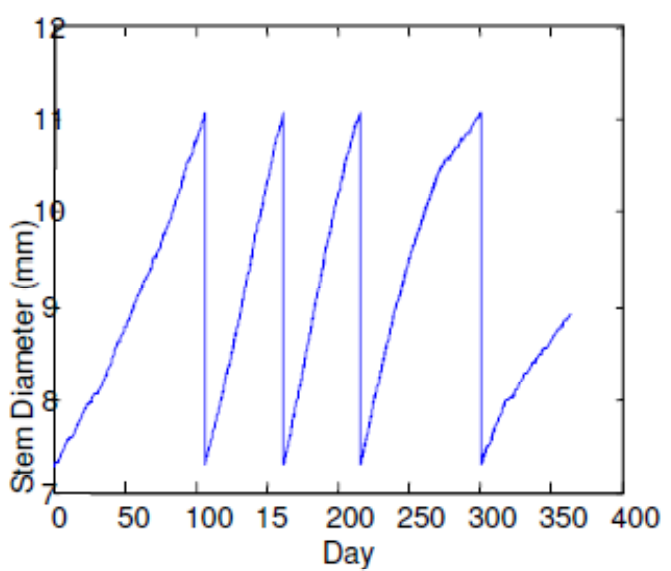

figure 2

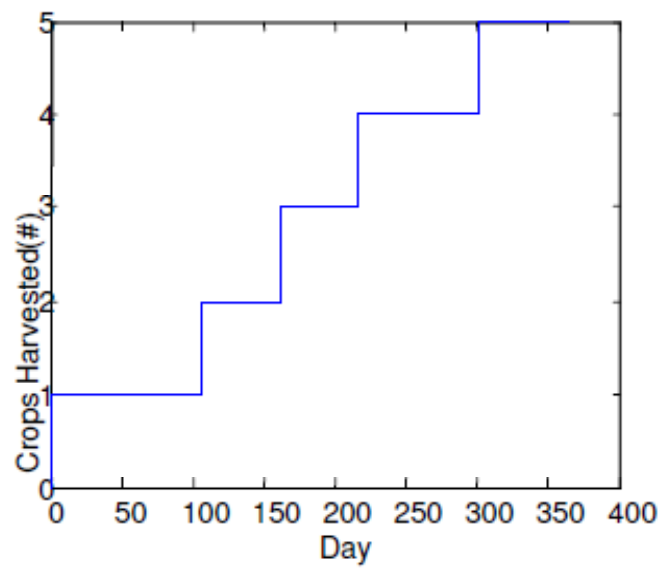

figure 4

Figure 1 is the height in $\mathbf{c m}$, Figure 4 is the cumulative number of growing season, Figure 3 is the total biomass (dry weight), and Figure 2 is the rod diameter in $\mathbf{m m}$

The speed of growth of the mass of the plant is normal for most of the year except in the end of autumn and beginning of winter because of the temperature drops at night and we discussed this problem and its correction previously. 